\title{
English Task Value: The Effect of Foreign Language Enjoyment and Foreign Language Anxiety
}

\author{
Jordain Riyadi Taufik ${ }^{1}$ Sri Tiatri ${ }^{1 *}$ Meylisa Permata Sari ${ }^{1}$
}

\author{
${ }^{1}$ Faculty of Psychology, Universitas Tarumanagara, Jakarta 11440, Indonesia \\ *Corresponding author. Email: sri.tiatri@ untar.ac.id
}

\begin{abstract}
This paper aims to investigate the role of foreign language enjoyment (FLE) and foreign language anxiety (FLA) on English task value (TV). It was hypothesized that foreign language enjoyment (FLE) and foreign language anxiety (FLA) had a role on English Task Value (TV). This research used quantitative nonexperimental methods and convenience sampling techniques, involving 163 high school students who completed the Foreign Language Anxiety (FLA), Foreign Language Enjoyment (FLE), and Motivated Strategies for Learning Questionnaire (MSLQ) questionnaires. The questionnaires were directly distributed to the participants and analyzed using the Multiple Regression Analysis. It was revealed that FLE had a significant role to TV $(\beta=.613, \mathrm{t}=9.176, \mathrm{p}<.05)$ while FLA did not have a significant role to TV $(\beta=.072, \mathrm{t}=1.081, \mathrm{p}$ $>.05$ ) with a total contribution of FLE and FLA to TV of $35.4 \%$ or $\mathrm{R}^{2}=35.4 \%$.
\end{abstract}

\section{Keywords: Foreign language anxiety (FLA), foreign language enjoyment (FLE), task value (TV)}

\section{INTRODUCTION}

Students' performance or academic achievement in foreign language subject can be predicted by emotions, namely negative and positive emotions. A study assessing the role of negative emotion during foreign language learning process was first conducted by Horwitz, Horwitz and Cope [18]. In this study, they found foreign language anxiety among participants. Foreign language anxiety (FLA) is defined as an incongruence of individuals' perceptions, belief, feelings, even behaviours which are shaped during language acquisition process. FLA consists of three components, namely communication apprehension, test anxiety, and fear of negative evaluation [18].

Horwitz et.al [18] had found that FLA had a negative correlation with the freshmen's scores in foreign language class during their first semester, indicating that the more anxious the individual, the lower the foreign language score was. In a similar vein, other recent studies showed that there was a negative correlation between FLA with the foreign language score and proficiency of a student in using English as foreign language $[3 ; 5 ; 24]$. Thus, the higher the FLA score, the worse the students performed and scored in foreign language subject.

Additionally, positive emotion, especially foreign language enjoyment (FLE), is also found to be correlated with students' foreign language score and performance $[5 ; 18]$. Foreign language enjoyment (FLE) reflects inviduals' willingness to elaborate their efforts in improving their attention and optimizing challenges when performing specific tasks, catalyzed by their satisfaction of learning the foreign language subject [1].
Dewaele and MacIntyre [6] divide FLE into two dimensions, namely FLE-private and FLE-social. FLEprivate is individuals' inner perception of foreign language subject, whereas FLE-social is associated with individuals' perception of their external surroundings, consisting of supports from educators and fellow students.

It was found that found that FLE correlated with increased motivation of learning and time of using foreign language among students [9]. In line, other recent studies showed that there was a positive correlation between FLE with the foreign language score $[5 ; 18]$. Thus, the higher the FLE, the higher the students' motivation of learning, time of using foreign language and the scores were.

Yet, it is argued that negative and positive emotions do not always directly predict academic performance. Hascher [14] concurs that the aspects of a task, such as its relevance, characteristics, and probability in failing or succeeding the task can mediate the role of emotions in academic learning process. Therefore, there is a need to further look into the role of emotions in the task aspects. To examine the role of emotions, furthermore, this study used the foreign language anxiety (FLA) and foreign language enjoyment (FLE). Meanwhile, the task aspects were examined through task value (TV).

Task value (TV) is defined as an internal perception or incentive of a task that affects individuals' decision in performing a task, consisting of four aspects, namely attainment value, intrinsic value, utility value and costs [28]. Attainment value represents the perceived significance of a task depending on the conception of individuals' identity, ideal self-schema and competence in a specific sphere of knowledge or activity. Intrinsic value, secondly, is personal enjoyment gained from task performance. When 
individuals consider intrinsic value of a task high, they will be highly interested in conducting tasks in a given domain. Utility value, thirdly, is a conception of the relevance of a task with one's ideals or goals in the present or future. Costs are perceived negative conceptions associated with certain tasks. Costs include performance anxiety, fear of both failure and success, perceived relationship between effort and performance, and perceived consequences of mistakes made during the completion of tasks [12].

Furthermore, an extensive number of studies showed that both positive and negative emotions are correlated with TV in certain domains. Yet, most of previous TV studies heavily focused on $[20 ; 21 ; 26]$. For example, studies conducted among 2508 middle school students in BadenWurtemberg by Trautwein et al. [27], among 6020 students in 275 middle schools in Germany by Kriegbaum et al. [20], and among 4306 students in 32 elementary schools in the Netherlands by Prast et al. [22] showed that TV had a negative correlation between mathematics TV and mathematics anxiety. Meanwhile, Schukajlow et al. [24] found a positive correlation between mathematics enjoyment and mathematics TV. Individuals therefore could deeply engage to and commit to the task when interested in the task. Thus, negative emotions and positive emotions have a role on task value.

On the other hand, a study on the role of emotions and TV in other domains, especially English language subject, namely FLA and FLE is still limited in number. Moreover, a series of studies FLA, FLE and TV in Indonesia is also rare. A study by Djafri \& Wimbarti's FLA study [10] mainly investigated the relation among FLA, students' motivation, and classroom learning. Additionally, their study revealed that FLA was non-significantly correlated with student motivation and could be reduced when teachers proactively created conducive atmosphere in the classroom. Another study by Purwanto [23] that merely focused on TV showed TV as an important aspect in the creation of the trident achievement motivation model, or model trisula motivasi berprestasi.

Overall, this study aims to investigate the FLA and FLE in English subject task value considering the number of English TV study is not as extensive as that of mathematics TV. Secondly, the study is propelled by the limited number of the study on FLA and FLE in Indonesia, especially among Indonesian high school students. The foreign language anxiety scale (FLA) used in this study is adopted from the foreign language anxiety in classroom scale (FLCAS) by Horwitz et al. [18], whereas the foreign language enjoyment (FLE) measurement is from Dewaele and MacIntyre [6]. Additionally, the foreign language used in this study is English, the most common foreign language spoken in 88 countries [13].

Based on the FLA, FLE, and English TV, there are two research questions proposed in this study. Firstly, what is the role of foreign language anxiety (FLA) in English TV? Secondly, what is the role of foreign language enjoyment (FLE) in English TV?

It was hypothesized that foreign language anxiety (FLA) and foreign language enjoyment (FLE) could act as a predictor of English TV.

\section{METHOD}

\subsection{Participants}

163 students were conveniently chosen to participate in this study. The participants were active senior high school students aged between 16 and 19 years old and attended compulsory English class at their respective school.

\subsection{Technique}

This study used convenience sampling method. According to Tabachnick and Fidell [26], the number of minimum samples required is $50+8 \mathrm{~m}$. $m$ is the number of predictor variables. Since this study used two predictor variables, the minimum partcipants required was 66 .

\subsection{Instruments}

Three measurement scales were employed in this study, namely Foreign Language Classroom Anxiety Scale (FLCAS), Foreign Language Enjoyment Scale (FLE), and Motivated Strategies for Learning Questionnaire (MSLQ). The items in the FLCAS represent communication apprehension, test anxiety, and fear of negative evaluation. In this study, 24 out of 33 items in the FLCA created by Horwitz et. al [18] were used. The unused items were items number $2,5,8,11,14,18,22,28$, and 32 . These items have been tested numerous times and lie between Cronbach Alpha of .86 and $.93[6 ; 16 ; 18]$. Meanwhile, in this study the reliability of the FLCAS as tested on Cronbach Alpha stood at $(\alpha)=.938$. FLCAS is measured using a standard 5point Likert scale, ranging from strongly disagree $=1$, disagree $=2$, neutral $=3$, agree $=4$, to strongly agree $=5$. The higher the students score in FLCA, the higher the level of students' FLA, or vice versa.

The second instrument is foreign language enjoyment (FLE) scale consisting of 21 items, which cover learning subscales, and peers support subscales, teacher support subscales. The scale created by Dewaele \& MacIntyre [6] and classified FLE as FLE private and FLE social. The learning subscales, items 1 to 13, were used to measure FLE private; whereas, both of the peer support (items 14, 18, 19, $20,21)$ and teacher support subscales $(15,16,17)$ were used to measure FLE social. Overall, all of these items have been tested numerous times and lie between Cronbach Alpha of .86 and $.92[6 ; 8 ; 9]$.

Meanwhile, in this study the learning, peer support, and teacher support sub-scales reliability stood at $(\alpha)=.771$, $(\alpha)=.737$, and $(\alpha)=.715$ respectively. FLE scale is measured using a standard 5-point Likert scale, ranging from strongly disagree $=1$, disagree $=2$, neutral $=3$, agree $=4$, to strongly agree $=5$. The higher the students score in FLE, the higher the level of students' FLE, or vice versa. The third instrument used is Motivated Strategies for Learning Questionnaire subscale intrinsic value (MSLQ). 
The MSLQ is created by Pintrich and Groot [21]. In total, there were 8 items chosen from the MSLQ, which were item number $5,6,9,12,17,18,21$, and 25 to measure TV. These items have been tested numerous times and lie between Cronbach Alpha of .87 and $.93[2 ; 11 ; 20]$. Meanwhile, the reliability of MSLQ was at $(\alpha)=.726$. MSLQ scale is measured using a standard 5-point Likert scale, ranging from strongly disagree $=1$, disagree $=2$, neutral $=3$, agree $=4$, to strongly agree $=5$.

\section{RESULTS}

Pearson's correlation test showed a positive correlation between FLE and TV $(r=.591, \mathrm{p}<.01)$. This indicates that the higher the participants' FLE score, the higher their TV score. The lower the participants' FLE score, the lower their TV score. On the other hand, it was found that there was a non-significant correlation between FLA and TV $(r=-.116$, $\mathrm{p}>.01)$. The results of Pearson's correlation analysis can be seen in Table 1 .

Table 1 Relationships of FLE and FLA with English TV

\begin{tabular}{llrlll}
\hline \multicolumn{6}{c}{ Correlations } \\
\hline & \multicolumn{1}{l}{ M } & \multicolumn{1}{l}{ FLE } & FLA & TV \\
FLE & 72.865 & 9.239 & 1 & & \\
FLA & 68.797 & 18.268 & $-.308^{* * *}$ & 1 & \\
TV & 31.490 & 3.897 & $.591^{* *}$ & -.116 & 1 \\
\hline
\end{tabular}

**. For significance at the 0.01 level (2-tailed).

*. For significance at the 0.05 level (2-tailed).

Furthermore, multiple regression test showed that FLE had a significant relation with TV, F $(2,160)=43.770, p<.000$, with $\mathrm{R}^{2}=.354$. Participants' FLE equals to $11.592+.259$ (TV). Participants' TV increased as much as .259 unit for each FLE. Meanwhile, it was found that FLA had a nonsignificant relation with TV, $p=.281>.05$. Therefore, only FLE could significantly predict TV. The results of multiple regression analysis can be seen in Table 2 .

Table 2 Summary of multiple regression analysis of FLA and FLE on TV $(\mathrm{N}=163)$

\begin{tabular}{|c|c|c|c|c|c|c|}
\hline \multirow{2}{*}{ Variable } & \multicolumn{3}{|l|}{ TV } & \multicolumn{2}{|c|}{$95 \% \mathrm{CI}$} & \multirow[b]{2}{*}{$p$} \\
\hline & $B$ & $S E B$ & $\beta$ & $L L$ & $U L$ & \\
\hline FLE & $\begin{array}{l}.25 \\
9\end{array}$ & .028 & .613 & .203 & .314 & .000 \\
\hline FLA & $\begin{array}{l}.01 \\
5\end{array}$ & .014 & .072 & -.013 & .044 & .281 \\
\hline$R^{2}$ & & .354 & & & & \\
\hline$F$ & & 43.77 & & & & \\
\hline
\end{tabular}

Note $. \mathrm{CI}=$ Confidence Interval, $\mathrm{LL}=$ Lower Limit, $\mathrm{UL}=$ Upper Limit

\section{DISCUSSION}

Hascher [15] states that negative emotion subjectively can direct subjects to focus on managing the feeling of discomfort caused by the negative emotion rather than on finding information, or accomplishing their tasks or academic activities.

On contrary, positive emotion can improve subjects' ability in processing and recalling information, perception and logical thinking process, creativity, being a non-conformist, and forming divergent thinking [15].

Another thing which can be highlighted is that if the assignment or activities are deemed unimportant, the impacts of emotion and mood will be more profound [15] Hence, negative emotion, especially FLA, can optimally function if English subject is considered trivial by subjects. Meanwhile, if English subject is considered important, FLA cannot function optimally.

Similarly, the impact of FLE as part of subject's positive emotion [15], can be higher when the task is considered unimportant. The function of positive emotion is implicitly discussed in two factors which compose TV.

Based on two out of three TV factors by Eccles and Wigfield [12], the intrinsic value is a conception of subjects' perceived enjoyment of performing a task or activity. In this case, English is perceived to provide a sense of enjoyment. Moreover, subjects who perceive English to be enjoyable will be self-motivated to explore their interest in the given domain.

Secondly, utility value is the perceived relevance of a task with a conception of both current and future ideals as well as circumstances [12]. In order to realize the utility value, positive emotion would act as a catalyst and support for the TV [15]. Indeed, positive emotion is needed by individuals to stay focus on and complete the tasks or activities [15]. Hence, it is expected that FLE has a role in TV and is correlated with TV.

\section{CONCLUSION}

This study found a significant role of FLE in English TV, and there was a non-significant role of FLA in English TV.

\section{SUGGESTIONS}

The findings revealed that there is a significant role of FLE in TV, but a non-significant role of FLA in TV. It can be deduced that the more enjoyable the students feel about a subject, the higher the TV of English subject. Therefore, it is highly necessary to keep students entertained so that the appreciation towards English subject increases [9]. For instance, educators and authorities should create studentcentred tasks / assignments, which are connected to students' experiences and behaviours. Other than the specific task, educators should also create conducive atmosphere by being approachable for the students and creating challenging as well as mysterious tasks. Additionally, the teachers can also promote cooperation among students [9].

Pertaining to the non-significant role of FLA in TV, it was suggested that teachers should focus on increasing 
enjoyment during the learning process [9]. Moreover, positive emotions, such as enjoyment, has three functions. Positive emotion has 'broaden impact' for individuals, enabling them to be flexible, inclusive, creative, systematic, open-minded and visioner. Additionally, positive emotion enables individual to be expansive, resourceful, socially connected, and to function optimally. This is known as the "build impact" of positive emotion. Lastly, positive emotion can undo the by-products of negative emotion, facilitating individuals to recover faster both physically and mentally after they experience a series of hurdles [15]. The improved physical conditions are usually seen in the measurement of heart rate, blood pressure, finger pulse index or even the index of peripheral vasoconstriction.

In relation to the future studies, furthermore, the researcher offers theoretical and practical suggestions. Firstly, the scope of the research can be expanded. In this study, the researcher conveniently sampled senior high school students from two high schools. Thus, future research can consider conducting the study using probability sampling method in deciding the criteria for participants. For example, ethnicities, socio-economic classes, and ages of the participants can be made more diverse in order to be able to generalize the findings for general populations. Additionally, future study can also be conducted at a regional or a national scale.

Another factor that should also be taken into consideration by future studies, the previous FLA scale used in this study, is rather outdated. Thus, it is highly necessary to search for more up-to-date references in order to ensure validity and reliability of the measurement scale.

Thirdly, future studies should consider examining the relationship between the FLA and FLE in English TV and students' English subject scores, while TV is used as mediator on the future research as in Hascher's Model [15]. Moreover, it is highly suggested that the questionnaires are distributed after the mid- or final exam period so that future studies can obtain optimum results.

\section{ACKNOWLEDGMENT}

The researcher would like to thank the participants involved in this research, Professor Elaine Kolker Horwitz as the pioneer of FLE's variable, Professor Jean-Marc Dewaele for giving researcher the authority to use FLCAS dan FLE scale, as well as the Faculty of Psychology, Universitas Tarumanagara, Jakarta.

\section{REFERENCES}

[1] Boudreau, C., MacIntyre, P. D., \& Dewaele, J. M. (2018). Enjoyment and anxiety in second language communication: An idiodynamic approach. Studies in
Second Language Learning and Teaching, 8(1), 149170. https://doi.org/10.14746/ssllt.2018.8.1.7

[2] Credé, M., \& Phillips, L. A. (2011). A meta-analytic review of the motivated strategies for learning questionnaire. Learning and Individual Differences, 21(4), 337-346.

[3] Dewaele, J. -M. (2013). The link between foreign language classroom anxiety and psychoticism, extraversion, and neuroticism among adult bi- and multilinguals. The Modern Language Journal. https://doi.org/10.1111/j.1540-4781.2013.12036.x

[4] Dewaele, J. -M. (2019). The effect of classroom emotions, attitudes toward english, and teacher behavior on willingness to communicate among english foreign language learners. Journal of Language and Social Psychology, 38(4), 523-535. https://doi.org/ $10.1177 / 0261927 \times 19864996$

[5] Dewaele, J. -M., \& Alfawzan, M. (2018). Does the effect of enjoyment outweigh that of anxiety in foreign language performance? Studies in Second Language Learning and Teaching, 8(1), 21-45. https://doi.org/ 10.14746/ssllt.2018.8.1.2

[6] Dewaele, J. -M., \& MacIntyre, P. D. (2014). The two faces of janus? Anxiety and enjoyment in the foreign language classroom. Studies in Second Language Learning and Teaching, 2, 237-274. https://doi.org/10.14746/ssllt.2014.4.2.5

[7] Dewaele, J. -M., \& MacIntyre, P. D. (2016). Foreign language enjoyment and foreign language classroom anxiety: The right and left feet of the language learner? In P. D. MacIntyre, T. Gregersen \& S. Mercer (Eds.), Positive psychology in SLA (pp. 215-236). Bristol, UK: Multilingual Matters.

[8] Dewaele, J. -M., Özdemir, C., Karci, D., Uysal, S., Özdemir, E. D., \& Balta, N. (2019). How distinctive is the foreign language enjoyment and foreign language classroom anxiety of kazakh learners of turkish? Applied Linguistics Review, 1-21. https://doi.org/10. 1515/applirev-2019-0021

[9] Dewaele, J. -M., Witney, J., Saito, K., \& Dewaele, L. (2017). Foreign language enjoyment and anxiety: The effect of teacher and learner variables. Language Teaching Research, 22(6), 676-697. https://doi.org/ $10.1177 / 1362168817692161$

[10] Djafri, F., \& Wimbarti, S. (2011). Measuring foreign language anxiety among indonesian undergraduate students in foreign language classroom: in relation with students' motivation and their 
perception toward teachers' behaviors. (Tesis tidak dipublikasikan). Fakultas Psikologi Universitas Gadjah Mada, Yogyakarta.

[11] Duncan, T., \& McKeachie, W. J. (2015). Motivated strategies for learning questionnaire (MSLQ). Mediterranean Journal of Social Sciences, 6(1), 156164. https://doi.org/10.5901/mjss.2015. v6n1p156

[12] Eccles, J. S., \& Wigfield, A. (2002). Motivational beliefs, values, and goals. Annual Review of Psychology, 53(1), 109-132.

[13] Education First. (2018). Ef epi 2018. Diunduh dari www.ef.com/epi

[14] Fredrickson, B. L. (2013). Positive emotions broaden and build. Advances in Experiemntal Social Psychology, 47, 1-53.

[15] Hascher, T. (2010). Learning and emotion: Perspectives for theory and research. European Educational Research Journal, 9(1), 13-28. https://doi.org/10.2304/eerj.2010.9.1.13

[16] Horwitz, E. K. (1986). Preliminary evidence for the reliability and validity of a foreign language anxiety scale. Tesol Quarterly, 20(3), 559-562.

[17] Horwitz, E. K. (2010). Foreign and second language anxiety. Language Teaching, 43(2), 154-167. https://doi.org/10.1017/S026144480999036X

[18] Horwitz, E. K., Horwitz, M. B., \& Cope, J. (1986). Foreign language classroom anxiety. The Modern Language Journal, 70(2), 125-132. https://doi.org/ 10.1111/j.1540-4781.1986.tb05256.x

[19] Jin, Y., \& Zhang, L. J. (2018). The dimensions of foreign language classroom enjoyment and their effect on foreign language achievement. International Journal of Bilingual Education and Bilingualism, O(0), 1-15. https://doi.org/10.1080/13670050.2018.1526253

[20] Kriegbaum, K., Jansen, M., \& Spinath, B. (2015). Motivation: A predictor of PISA's mathematical competence beyond intelligence and prior test achievement. Learning and Individual Differences, 43, 140-148.

[21] Pintrich, P. R., \& De Groot, E. V. (1990). Motivational and self-regulated learning components of classroom academic performance. Journal of Educational Psychology, 82(1), 33.

[22] Prast, E. J., Van de Weijer-Bergsma, E., Miočević, M., Kroesbergen, E. H., \& Van Luit, J. E. (2018).
Relations between mathematics achievement and motivation in students of diverse achievement levels. Contemporary Educational Psychology, 55, 84-96.

[23] Purwanto, E. (2014). Model motivasi trisula: Sintesis baru teori motivasi berprestasi. Jurnal Psikologi, 41(2), 218-228.

[24] Schukajlow, S., Leiss, D., Pekrun, R., Blum, W., Müller, M., \& Messner, R. (2012). Teaching methods for modelling problems and students' task-specific enjoyment, value, interest and self-efficacy expectations. Educational studies in mathematics, 79(2), 215-237.

[25] Shao, K., Yu, W., \& Ji, Z. (2013). An exploration of chinese EFL students' emotional intelligence and foreign language anxiety. Modern Language Journal, 97(4), 917-929. https://doi.org/10.1111/j.1540-4781. 2013.12042.x

[26] Tabachnick, B. G., \& Fidell, L. S. (2014). Using multivariate statistics (new international ed. ed.). Harlow: Pearson.

[27] Trautwein, U., Marsh, H. W., Nagengast, B., Lüdtke, O., Nagy, G., \& Jonkmann, K. (2012). Probing for the multiplicative term in modern expectancy-value theory: A latent interaction modeling study. Journal of Educational Psychology, 104(3), 763.

[28] Wigfield, A., \& Eccles, J. S. (1992). The development of achievement task values: A theoretical analysis. Developmental Review, 12(3), 265-310. https://doi.org/10.1016/0273-2297(92)90011-P 